\title{
Integration and expression of Bluetongue VP2 gene in somatic embryos of peanut through particle bombardment method
}

\author{
T.N. Athmaram, Geetha Bali*, K.M. Devaiah \\ Department of Microbiology and Biotechnology, Bangalore University, Jnanabharathi, Bangalore 560056, India
}

Received 20 September 2005; received in revised form 2 November 2005; accepted 8 November 2005

Available online 1 December 2005

\begin{abstract}
After pre-culture and treatment of osmosis, zygotic embryos of peanut (Arachis hypogaea L.) were transformed via particle bombardment with a plasmid containing a Bluetongue VP2 gene (BTVP2) comprising neutralizing epitopes. Selection for Kanamycin resistant calluses and somatic embryos was initiated at 12 th day post-bombardment on medium containing $25 \mathrm{mg} / \mathrm{L} \mathrm{Kanamycin.} \mathrm{Under} \mathrm{continuous} \mathrm{selection,}$ $12.38 \%$ Kanamycin resistant plantlets were regenerated from bombarded somatic embryos. The presence and integration of BTVP2 DNA in regenerated Kanamycin resistant plants were confirmed by southern hybridization assay using non-radioactive Digoxiginin BTVP2 probe. $\beta$-Glucuronidase (GUS) enzyme activity was detected in transgenic somatic embryos but not from control, non-transformed embryos. The expression of the BTVP2 protein was confirmed through RT-PCR (reverse transcription polymerase chain reaction) using the RNA isolated from the transgenic callus employing BTVP2-specific primers. The production of transgenic peanut was mainly focused on evaluating a newly improved somatic embryogenesis regeneration system as well as the gene transfer method and to produce the Bluetongue outer coat protein that comprises the neutralizing epitopes.
\end{abstract}

(C) 2005 Elsevier Ltd. All rights reserved.

Keywords: Peanut (Arachis hypogaea); Somatic embryo; BTVP2 protein; Particle bombardment

\section{Introduction}

Bluetongue (BT) is primarily a disease of sheep distributed in almost all tropical and subtropical countries of the world. Goats, cattle and wild ruminants are also affected to variable degrees. Bluetongue virus (BTV), the causative agent of the disease, is a double stranded RNA virus of Orbivirus genus within the family Reoviridae. Midges belonging to the genus Culicoides transmit the virus [1]. The major antigenic determinant of BTV is encoded by VP2 gene that constitutes the outer capsid of the virus [2,3]. Hence, the major antigenic determinant part of the VP2 protein comprising neutralizing epitopes was selected for expression in peanut with a view to develop a potential and cost effective subunit vaccine in plant system for efficient control of Bluetongue disease.

\footnotetext{
* Corresponding author. Tel.: +91 8022961461.

E-mail address: baliccet@vsnl.com (G. Bali).
}

Arachis hypogaea L., peanut or groundnut, is an important commercial crop worldwide and provides an excellent source of protein and other nutrients and hence peanut was selected to express the BTVP2 gene. Transgenic peanut plants have been produced by particle bombardment [4] and via Agrobacterium-mediated transformation [5]. Microprojectile bombardment uses high velocity particles to penetrate cell walls and to deliver DNA into intact plant cells. Microprojectile bombardment is the method of choice to overcome the host-specific limitation associated with the use of Agrobacterium for transformation [6].

Many researchers have reported the regeneration systems by somatic embryogenesis induced by 2,4-dichlorophenoxyacetic acid (2,4-D) using different kinds of explants, such as cotyledons, leaflet, axes $[7,8]$. However, there are very few reports on the production of transgenic plants using these regeneration systems. Recently, we have developed a newly improved and more efficient regeneration system via somatic embryogenesis induced by 2,4-D using zygotic embryos and 
also have developed a particle bombardment transformation system for peanut and have obtained transgenic somatic embryos carrying BTVP2 gene. Integration and expression of the target gene within the plant genome was confirmed through Southern hybridization assay and RT-PCR, respectively. This is the first report on expression of BTVP2 protein in a plant system in general and peanut in particular.

\section{Materials and methods}

\subsection{BTV and BTVP2 gene isolation}

BTV serotype 23 propagated in Baby Hamster Kidney21 (BHK-21) cell line was used in the present study and the BTVP2 gene specific primers employed were

\section{VP2LT: 5' G GTA AAA ATA GTG TCG CGA TGG A 3' and VP2RT: 5' GTA TCG GAA GCT TCA ATC AT 3'.}

Total RNA from BTV infected BHK-21 cells were extracted using Trizol ${ }^{\circledR}$ reagent (Gibco BRL, USA) method and was further subjected to cDNA synthesis at $42{ }^{\circ} \mathrm{C}$ for $60 \mathrm{~min}$ using Moloney murine leukemia virus (M-MLV) reverse transcriptase enzyme with VP2-specific primers. The cDNA was amplified through PCR employing the same primers [9]. The PCR was carried out under the following conditions: $94^{\circ} \mathrm{C}$ for $45 \mathrm{~s}, 59{ }^{\circ} \mathrm{C}$ for $40 \mathrm{~s}, 72{ }^{\circ} \mathrm{C}$ for $50 \mathrm{~s}$, for 35 cycles and finally $72^{\circ} \mathrm{C}$ for $10 \mathrm{~min}$. The amplified PCR product was cloned into linearized pDRIVE cloning vector (Qiagen) and the construct, pDRIVEBTVP2 was mobilized into DH5 alpha E. coli electrocompetant cells via electroporation using eppendorf electroporator [10]. The recombinant colonies were selected and the gene integrated within the vector was characterized through nucleotide sequencing from $5^{\prime}$ and $3^{\prime}$ ends using vector-specific primers. The sequencing reactions were carried out using the ABI 377 Perkin-Elmer automated DNA sequencer. Further, the target gene was amplified from pDRIVEBTVP2 DNA through PCR using the same primer sequences except for addition of $N c o$ I and $B g l$ II restriction sites in forward and reverse primers respectively to facilitate the insertional event of the target gene in pCAMBIA 2301 binary vector.

\subsection{Peanut material, media and pre-culture experiments}

Immature pods were harvested after pollination from 50 days old A. hypogaea cultivar JL24 grown in the greenhouse in pots containing a 1:1 (v/v) mixture of sand and field soil. Pods were first washed in tap water followed by a mild detergent solution and were further transferred to laminar Hood. The pods were rinsed in $70 \%$ (v/v) ethanol for $5 \mathrm{~min}$, then sterilized using $0.1 \%$ mercuric chloride for $15 \mathrm{~min}$ followed by two washes with sterile water. Immature seeds were removed from the surface-cleaned pods, then the immature embryos were removed from the seed, and the zygotic embryos were carefully removed under sterile condition without damaging and given a quick rinse in $70 \%$ ethanol for two min. followed by three rinses with sterile water. The sterile embryos were cultured on a $90 \mathrm{~mm}$ Perish dish containing $30 \mathrm{ml}$ callus induction medium consisting Murashige and Skoog (MS) salts and B5 vitamins, $0.8 \%$ agar, $3 \%$ sucrose with varied concentration of 2,4-D (5, 10, 20, 30, 40 and $50 \mathrm{mg} / \mathrm{L})$ [8]. The $\mathrm{pH}$ of the medium was 6.0. All cultures were grown in the dark at $28^{0} \mathrm{C}$.

The effects of pre culture and osmosis treatment on transformation were checked as previously described [11]. After 1-7 days of pre-culture in induction medium, part of the pre-cultured embryos were treated for $1-3 \mathrm{~h}$ by osmosis medium (induction medium containing $0.4 \mathrm{M}$ mannitol) and the embryos were used for particle bombardment. After being cultured in the induction medium for 10 days postbombardment, the embryos were used for $\beta$-glucuronidase (GUS) analysis and GUS expression spots on the whole embryo and within the cells were observed under microscope. In another experiment, somatic embryos were cultured in the induction medium containing different concentrations of Kanamycin to check the antibiotic sensitivity of the peanut embryos before bombardment.

\subsection{Construction of recombinant binary plasmid with BTVP2 gene and Microprojectile bombardment}

BTV-VP2 gene was ligated into binary vector pCAMBIA2301 at NcoI and BglII sites down stream to CaMV $35 \mathrm{~S}$ promoter and the chimera was labeled as pCAMBIABTVP2. The recombinant plasmid was transferred into $E$. coli DH5 alpha electrocompetant cells via electroporation [10]. Recombinant colonies harboring pCAMBIABTVP2 were selected through restriction digestion analysis of the plasmid and PCR. The plasmid DNA was isolated from E. coli by the alkaline lysis method and was purified with Qiagen plasmid purification kit before using for bombardment. The purified plasmid was coated onto tungsten microcarriers and was bombarded twice consecutively using a PDS 1000/helium-driven apparatus (Bio-Rad, CA, USA) under sterile conditions with the somatic embryos arranged in a circle of $2-3 \mathrm{~cm}$ diameter. Each plate had 7-12 precultured embryos that were incubated in osmotic medium for 1-3h. The acceleration with which the microcarriers were bombarded with the explants was 1200 psi and the sample platform was positioned $5 \mathrm{~cm}$ below the launch assembly in all experiments. Each bombardment delivered approximately $1 \mathrm{mg}$ DNA and $300 \mathrm{mg}$ tungsten particle $1.0 \mathrm{~mm}$ in diameter [7,11]. Selection for Kanamycin resistant somatic embryos was initiated on the 12th day of post-bombardment on M.S medium containing 30-50 mg/L Kanamycin. Under continuous selection, Kanamycin resistant somatic embryos were generated. The integration and expression of target DNA in regenerated Kanamycin resistant peanut embryos was confirmed by RT-PCR using BTV VP2 gene specific primers and also by GUS assay in trans- 
genic embryos against non-transformed embryos as control [12].

\subsection{Pre-culture, osmosis treatment and the regeneration of Kanamycin-resistant plants}

Different 2,4-D concentrations ranging from 5 to $50 \mathrm{mg} / \mathrm{L}$ were tested to obtain good embryogenic callus before transformation experiments and the optimum 2,4-D concentration was determined. After 1-7 days of pre-culture in induction medium, embryos were transferred to osmotic medium containing 0.4 M mannitol. Bombardments were carried out after different incubation intervals like 1,2 and $3 \mathrm{~h}$ in the osmotic medium having constant concentration of Mannitol. After bombardment, the embryos were incubated in the same medium for $16 \mathrm{~h}$ and then transferred into fresh induction medium and incubation was continued for about 10 days. For checking the transformation process, few embryos were subjected to GUS assay and the remaining were transferred to fresh selection medium (induction medium with each of 30mg/L 2,4-D and Kanamycin). After 14 days, somatic embryos were transferred to fresh selection media for another 14 days. Surviving embryos with newly formed embryogenic calluses were transferred into solid selection medium containing $30 \mathrm{mg} / \mathrm{L}$ Kanamycin and $10 \mathrm{mg} / \mathrm{L} \mathrm{2,4-D} \mathrm{for} \mathrm{weekly}$ subculture. Small portion of the tissue was aseptically separated from the putatively transformed embryogenic calluses and were subjected to Southern hybridisation and RT-PCR analysis for early confirmation of the target gene integration and expression respectively. The regeneration process of surviving positive transformed embryos in the selection medium into complete plants is underway.

\section{5. $\beta$-Glucuronidase (GUS) assay}

Expression of GUS gene was confirmed by the GUS assay [13]. The assay solution contained $0.5 \mathrm{mM}$ potassium ferricyanide, $0.5 \mathrm{mM}$ potassium ferrocyanide, $0.3 \%(\mathrm{v} / \mathrm{v})$ Triton X-100, and $1 \mathrm{mg} / \mathrm{ml}$ 5-bromo-4-chloro-3-indolyl $\beta$ D-glucuronide (X-gluc) in $50 \mathrm{mM}$ phosphate buffer, $\mathrm{pH}$ 7.0. Somatic embryos were randomly collected from Kanamycin plates and were placed in a micro-centrifuge tube containing about $0.8 \mathrm{ml}$ assay solution. The tubes were incubated for $24 \mathrm{~h}$ at $37^{\circ} \mathrm{C}$. The sample buffer was discarded and materials were washed by $95 \%(\mathrm{v} / \mathrm{v})$ ethanol. Thin sections were taken from the putative transformants and blue spots localized within the cells were observed under the microscope.

\subsection{Southern hybridization and RT-PCR analysis}

DNA was extracted from the regenerating embryogenic callus and subjected to southern hybridization assay using newly constructed BTVP2-specific non-radioactive digoxiginin probe for early detection of BTVP2 gene. The heat denatured DNA samples were spotted and transferred onto nitrocellulose membrane. Further, the DNA was hybridized with target gene specific probe and the hybridization was detected using anti-DIG alkaline phosphatase [14] employing Hybrimax hybridization unit (Hongkong). RNA was extracted from the tissue that were found positive with southern hybridisation assay using Qiagen RNA preparation kit as per the manufacturer's protocol and was directly used for RT-PCR employing BTVP2-specific primers [15]. After RT-PCR, the samples were assayed by electrophoresis in $1.5 \%$ agarose gels for the presence of $1064 \mathrm{bp}$ amplicon.

\section{Results and discussion}

Effect of pre-culture, osmosis treatment and Kanamycin concentration on transformation were studied and it was evident that the pre-culture and osmosis treatment are critical for transformation in terms of the number of surviving embryos after bombardment under Kanamycin (Table 1). The pre-culture process in the induction medium followed by osmotic medium influenced the competence for transformation of bombarded epidermal and subepidermal cells of the zygotic embryos. Five days of pre-culture had good number of transformants and hence was considered to be optimal duration of pre-culture before bombardment. Serious damage followed by death was observed both in case of embryos those were directly used for bombardment without pre-culturing on induction medium and without incubation in osmotic medium. More number of embryos survived after bombardment in case embryos that had 5 days of preculture and $3 \mathrm{~h}$ of incubation in osmotic medium (Fig. 1A). It is known that osmosis can alleviate the damage caused after bombardment [11], and incubation in mannitol helps in decreasing such damages after bombardment. Maximum survival was observed when the 5 days precultured embryos were used with $3 \mathrm{~h}$ of incubation in osmosis medium prior to bombardment (Table 1). Our findings are in accordance with the observations made earlier employing GUS analysis

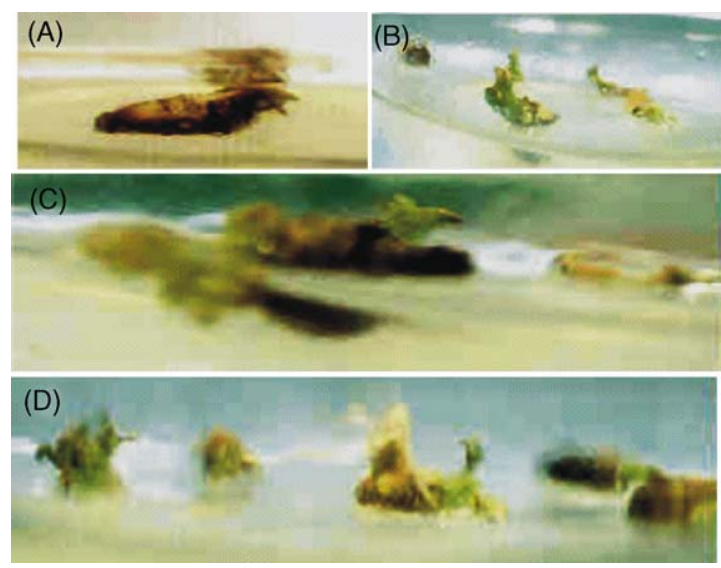

Fig. 1. (A-D) In vitro culture of peanut somatic embryos after bombardment with pCAMBIABTVP2 under Kanamycin selection at different stages of growth. 
Table 1

Table showing the transformation efficiency in peanut embryos with different pre-culture and osmosis treatments

\begin{tabular}{|c|c|c|c|c|}
\hline S1. no. & Pre-culture (days) & Osmosis treatment $(\mathrm{h})$ & No. embryos used for bombardment & Average no. of survivals under Kanamycin selection \\
\hline \multirow{3}{*}{1} & \multirow{3}{*}{1} & 1 & 30 & 00 \\
\hline & & 2 & 30 & 00 \\
\hline & & 3 & 30 & 00 \\
\hline \multirow{3}{*}{2} & \multirow{3}{*}{2} & 1 & 30 & 00 \\
\hline & & 2 & 30 & 00 \\
\hline & & 3 & 30 & 01 \\
\hline \multirow{3}{*}{3} & \multirow{3}{*}{3} & 1 & 30 & 03 \\
\hline & & 2 & 30 & 04 \\
\hline & & 3 & 30 & 05 \\
\hline \multirow{3}{*}{4} & \multirow{3}{*}{4} & 1 & 30 & 04 \\
\hline & & 2 & 30 & 05 \\
\hline & & 3 & 30 & 05 \\
\hline \multirow{3}{*}{5} & \multirow{3}{*}{5} & 1 & 30 & 06 \\
\hline & & 2 & 30 & 08 \\
\hline & & 3 & 30 & 10 \\
\hline \multirow{3}{*}{6} & \multirow{3}{*}{6} & 1 & 30 & 04 \\
\hline & & 2 & 30 & 05 \\
\hline & & 3 & 30 & 05 \\
\hline \multirow{3}{*}{7} & \multirow{3}{*}{7} & 1 & 30 & 03 \\
\hline & & 2 & 30 & 04 \\
\hline & & 3 & 30 & 06 \\
\hline TOTAL & & & 630 & 78 \\
\hline
\end{tabular}

for checking the transformation efficiency [11]. Forty milligrams per liter concentration of 2,4-D used in the induction medium had good proliferation amongst all concentrations tested. For selection of transformants, the Kanamycin sensitivity test was undertaken to see the maximum concentration of the antibiotic that the peanut embryos can withstand prior to transformation. It was observed that at $50 \mathrm{mg} / \mathrm{L}$ concentration of Kanamycin, none of the embryos survived while the number of survivals increased with decreasing concentrations (data not shown). Hence, $40 \mathrm{mg} / \mathrm{L}$ was selected for screening and selection of the transformants after bombardment.

\subsection{Selection of Kanamycin resistant calluses and their regeneration}

Embryos were cultured in induction medium for 10 days after bombardment and were then transferred onto selection medium. The untransformed embryogenic calluses during selection died slowly and some survived and grew well. These Kanamycin resistant calluses (Fig. 1B) were transferred into liquid selection medium containing $40 \mathrm{mg} / \mathrm{L}$ Kanamycin. During further selection, more Kanamycin-resistant somatic embryos were formed (Fig. 1C and D). All Kanamycin resistant somatic embryos were subjected to regeneration into Kanamycin resistant plantlets. From the results (Table 1), it is evident that the average number of transformed embryos that survived in Kanamycin selection medium after bombardment is 78 out of 630 total number of embryos used with about
$12.38 \%$ transformation efficiency. The Kanamycin-resistant embryos are being cultured in the regeneration medium to develop complete plants.

\subsection{GUS assay of transformed embryos}

Few somatic embryos were randomly collected from Kanamycin plates and were assayed for GUS expression. Blue stains were observed on the transformed embryos (Fig. 2A) indicating successful transformation. Histological studies made from thin sections taken from the blue embryos revealed localized blue spots within the cells under microscope (Fig. 2B and C).

\subsection{Southern hybridization and RT-PCR analysis}

Upon subjecting the DNA samples extracted from Kanamycin resistant embryogenic calli to southern hybridization, signals were observed in five DNA samples along with positive control (pDRIVEBTVP2 plasmid DNA) whereas negative control (DNA from embryos transformed with pCAMBIA2301 without insert) did not develop any signals (Fig. 3). This confirmed the integration of BTVP2 gene within the peanut genome. RNA samples extracted from the regenerating peanut embryogenic calli that were found positive through southern hybridization were screened for the expression of the integrated BTVP2 gene using RT-PCR. Following RT-PCR, one sample showed amplification of 1064bp DNA. Whereas RNA from negative control (embryo 

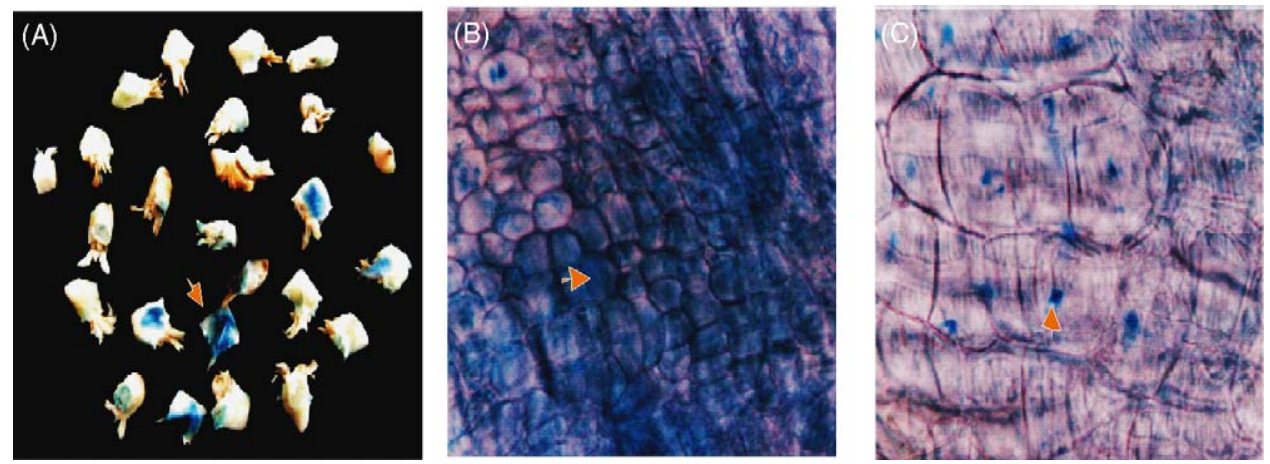

Fig. 2. GUS assay of transgenic peanut embryos (marked with arrow): (A) GUS spots on somatic embryos bombarded with pCAMBIABTVP2; (B and C) histological sections of Kanamycin resistant embryogenic calli after GUS assay showing expression of GUS gene within them.

transformed with pCAMBIA2301 without insert) did not show any band (Fig. 4). This confirmed the expression of the integrated BTVP2 gene. Separation of mRNA from total RNA was avoided, as we were able to generate positive signal with RNA sample directly after RT-PCR. However, demonstration of the expressed protein through western blotting is required to check the specificity of the protein.

As our main aim at this stage was only to develop a method for transferring Bluetongue VP2 gene into peanut using particle bombardment method, studies pertaining to the immunogenicity of the expressed protein and other characterization of the protein were beyond the scope. The transgenic somatic embryos of peanut carrying BTVP2 gene have promising applications in future. The regenerated transgenic plants can be used in producing Bluetongue subunit vaccine that would be valuable for vaccination programmes in developing countries where Bluetongue disease is endemic. The

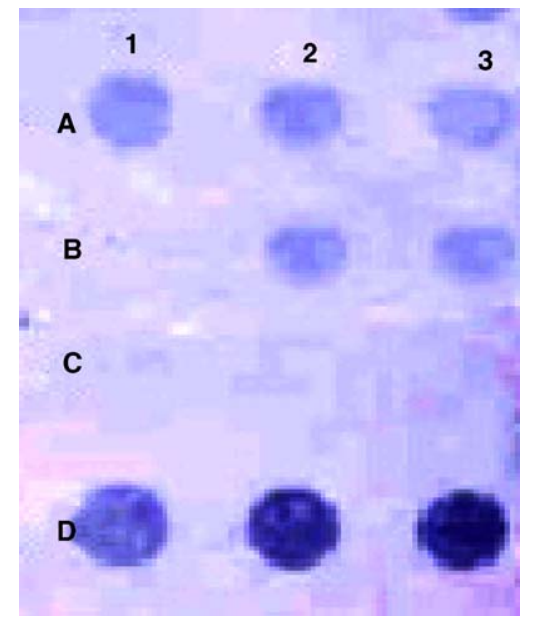

Fig. 3. Southern hybridization assay to confirm the integration of BTVP2 gene within the genome of somatic embryos. (A1, 2, 3 and B1, 2, 3)-Test samples: DNA samples from six Kanamycin resistant somatic embryos bombarded with pCAMBIABTVP2. (C1, 2, 3)—Negative control: DNA samples from three Kanamycin resistant somatic embryos bombarded with pCAMBIA2301 without insert. (D1, 2, 3)—Positive control: plasmid DNA from pDRIVEBTVP2. proliferating transgenic callus may also be used as bioreactors for producing BTVP2 protein in suspension cultures. As conditions for the cultivation of peanut is well established in many countries, immunization could potentially be achieved by feeding the animals with the transgenic peanut plants or the products derived from these plants (Fig. 5). The vaccine protein expressed in plant tissues also eliminates the risk of contamination with animal pathogens, provides a heat-stable environment and enables oral delivery, thus eliminating injection-related hazards. Hence, the current study is invaluable preparing the necessary background for testing the feasibility of developing a potential edible subunit vaccine for Bluetongue viral disease that has threatened sheep farming community.

In summary, we have successfully obtained transgenic peanut embryos carrying Bluetongue VP2 gene through particle bombardment method. The integrated gene is being expressed as evident from RT-PCR analysis. As far as we know, this is the first report of its kind on expression of BTVP2 protein in the plant system in general and peanut in particular.

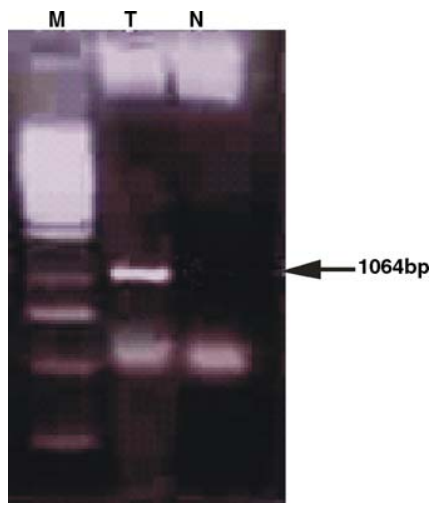

Fig. 4. RT-PCR analysis for expression of BTVP2 gene within kanamycin resistant embryogenic callus. M: molecular weight marker (MBI Fermentas,USA); T: Kanamycin resistant callus transformed with pCAMBIABTVP2 showing amplification of 1064 bp DNA; N: negative controlKanamycin resistant callus transformed with pCAMBIA2301 without insert. 


\section{STRATEGY FOR DEVELOPING BLUETONGUE EDIBLE SUBUNIT VACCINE}

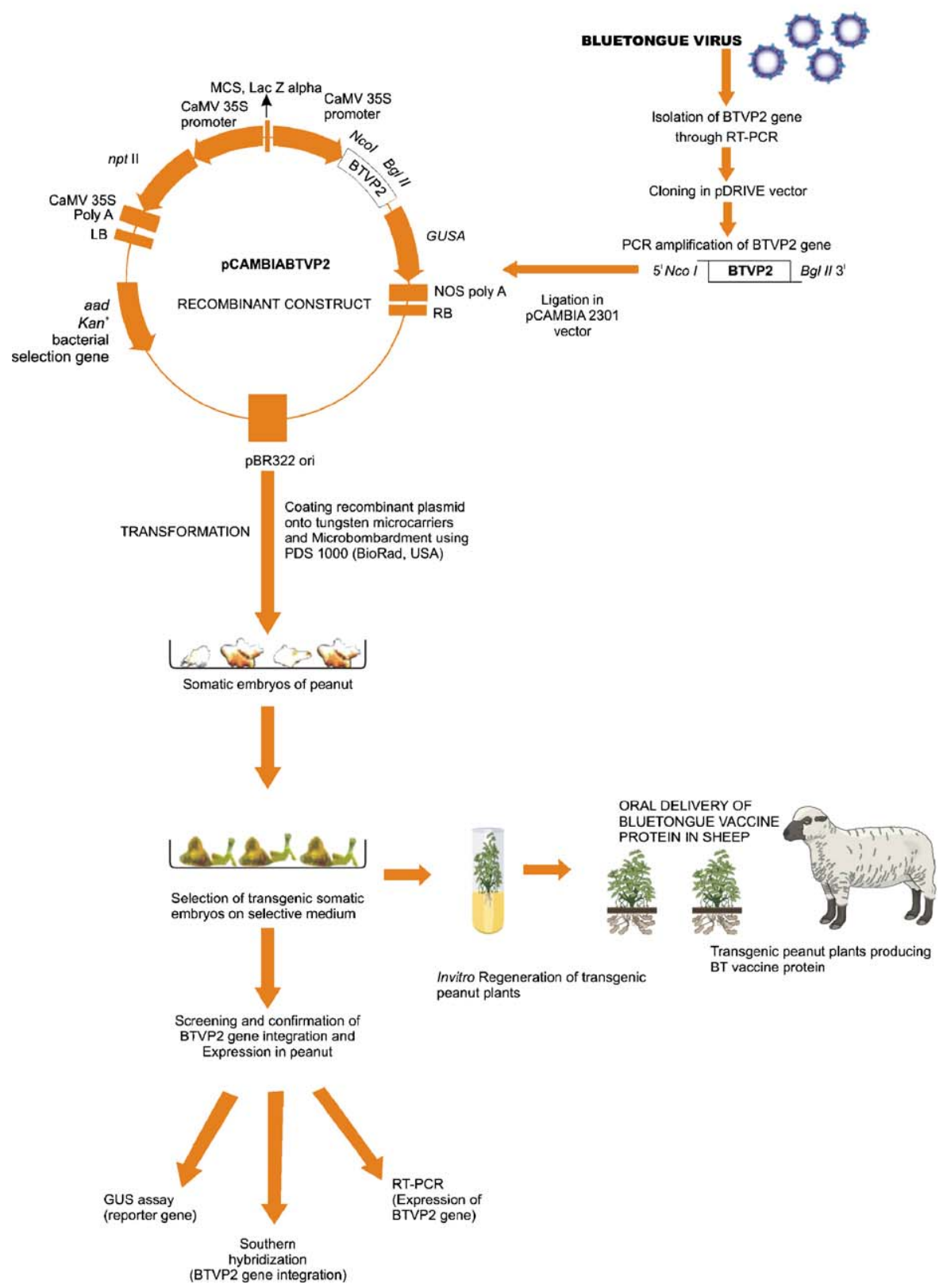

Fig. 5. Schematic diagram involving the whole process of developing Bluetongue edible subunit vaccine.

\section{Acknowledgments}

The authors are thankful to the Institute of Animal Health and Veterinary Biologicals, Bangalore for providing facilities during the initial studies. We thank Prof. T.K.S. Gowda, Department of Biotechnology, University of Agricultural Sciences, Bangalore for providing Genegun facility. We also acknowledge Mr. Renukaradhya Math, Mr. Balaji O.A., Mr. Vaidyanathan G., and Mr. Sanjeev B.S. for their assistance during this study.

\section{References}

[1] Huismans H, Van Der Walt NT, Cloete M, Erasmus BJ. Isolation of a capsid protein of bluetongue virus that induces a protective immune response in sheep. Virology 1987;61:3589-95.

[2] Bonneau KR, Topol JB, Gerry AC. Variation in the NS3/3A genes of bluetongue viruses contained in Culicoides sonorensis collected from a single site in southern California. Virus Res 2002;84:59-65.

[3] Gould AR. Conserved and non-conserved regions of the outer coat protein VP2 of the Australian Bluetongue serotype1 virus revealed By sequence comparison to the VP2 of North American BTV serotype10. Virus Res 1988;9:145-58. 
[4] Wang A, Fang H, Singsit C, Ozias-Akins P. Transformation of peanut with a soybean vsp B promoter-uidA chimeric gene optimization of a transformation system and analysis of GUS expression in primary transgenic tissue and plants. Physiol Plant 1998;102:3848.

[5] Cheng M, Jarret RL, Li Z, Xiang A, Demski JW. Production of fertile transgenic peanut (Arachis hypogaea L.) plants using Agrobacterium tumefaciens. Plant Cell Rep 1996;15:653-8.

[6] Klein TM, Wolf ED, Wu R, Sanford JC. High velocity microprojectiles for delivering nucleic acids into living cells. Nature 1987;327:70-3.

[7] Hazra S, Sathaye SS, Mascarenhas AF. Direct somatic embryogenesis in peanut (Arachis hypogaea L.). Bio Technology 1989;7:94951.

[8] Mckently AH. Direct somatic embryogenesis from axes of mature peanut embryos. In vitro Cell Dev Biol 1991;27:197-200.

[9] Akita GY, Chinsangram J, Osburn BI, Ian Conescu M, Kaufman R. Detection of bluetongue virus in clinical samples by polymerase chain reaction. J Vet Diagn Invest 1992;5:154-8.
[10] Sambrook J, Fritsch EF, Maniatis T. Molecular cloning: a laboratory manual. Cold Spring Harbor, NY: Cold Spring Harbor Laboratory Press; 1989.

[11] Deng XY, Zhi Ming WEI, Hai Long AN. Transgenic peanut plants obtained by particle bombardment via somatic embryogenesis regeneration system. Cell Res 2001;11(2):156-60.

[12] Namdadeva YL, Lup CG, Meyer CS, Devi PS, Potrykus I, Bilang R. Microprojectile-mediated transient and integrative transformation of rice embryogenic suspension cells: effects of osmosis cell conditioning and of the physical configuration of plasmid DNA. Plant Cell Rep 1998;18:500-4.

[13] Jefferson RA. Assaying chimeric genes in plants: the gus gene fusion system. Plant Mol Bio Rep 1987;5:387-405.

[14] Roy P, Ritter Jr GD, Akashi H, Collisson E, Inaba Y. A genetic probe for identifying bluetongue virus infection in vivo and in vitro. J Gen Virol 1985;66:1613-9.

[15] Johnson DJ, Wilson WC, Paul PS. Validation of reverse transcriptase multiplex PCR test for the serotype determination of US isolates of bluetongue virus. Vet Microbiol 2000;76:105-15. 